\title{
Observations of gonadotrophic and ovarian hormone activity during recovery from anorexia nervosa
}

\author{
A. H. CRISP \\ M.D., F.R.C.P.Ed., F.R.C.Psych. \\ C. CHEN \\ M.B., D.P.M.
}

Academic Department of Psychiatry, St George's Hospital Medical School, Tooting, London, S.W.17

\author{
P. C. B. MACKINNON \\ M.A., M.B., Ph.D. \\ C. S. CORKER \\ B.Sc., D.Phil. \\ M.R.C. Neuroendocrinology Unit,
Department of Human Anatomy,
University of Oxford
}

for the amenorrhea. If clomiphene citrate, whicho normally stimulates pituitary gonadotrophin secreo tion, is administered at this stage, it fails to cause an? increase in gonadotrophin secretion. However, when considerable weight has been regained the drug is effective (Marshall \& Russell Fraser, 1971). Frome the results of these investigations it has been suggested that anorexia nervosa is also associate with a disturbance of hypothalamic function. TTe $e^{\omega}$ nature of the probable interaction between psychological and hypothalamic disturbances, how-s ever, remains unclear.

In the present study six unmarried female subjectso with anorexia nervosa were admitted to hospital for treatment aimed in the usual way at not only $\overrightarrow{\vec{F}}$ restoring their weight to exactly that of a healthy population (matched for sex, height and age at? which the patient fell ill), but also at attempting through discussions with them and their families, to enable them to develop a more realistic assessment 3 . of and capacity to cope with themselves and theiro environment in their renewed 'post-pubertal' state (Crisp, 1967).

The patients were each admitted for a period of 3-5 months. They remained in bed throughout the 9 time of weight gain, eating a 2500-3000 calorie $>$ 'normal' diet daily, including adequate amounts of carbohydrate, and thereafter they were slowly mobilized as described elsewhere (Crisp, 1970). The levels of plasma luteinizing hormone (LH), follicle ${ }^{N}$ stimulating hormone (FSH) and ovarian steroid hormones in these patients before and duringo weight gain are presented in this paper.

\section{Patients and methods}

Some of the clinical details of the six patients are $\frac{T}{+}$ given in Table 1. Blood samples for estimation of $\frac{+}{\circ}$ gonadotrophin and gonadal steroid levels were $\stackrel{?}{\circ}$
(LH) levels (Marshall \& Russell Fraser, 1971 ; Beumont, 1972) are low and probably account 

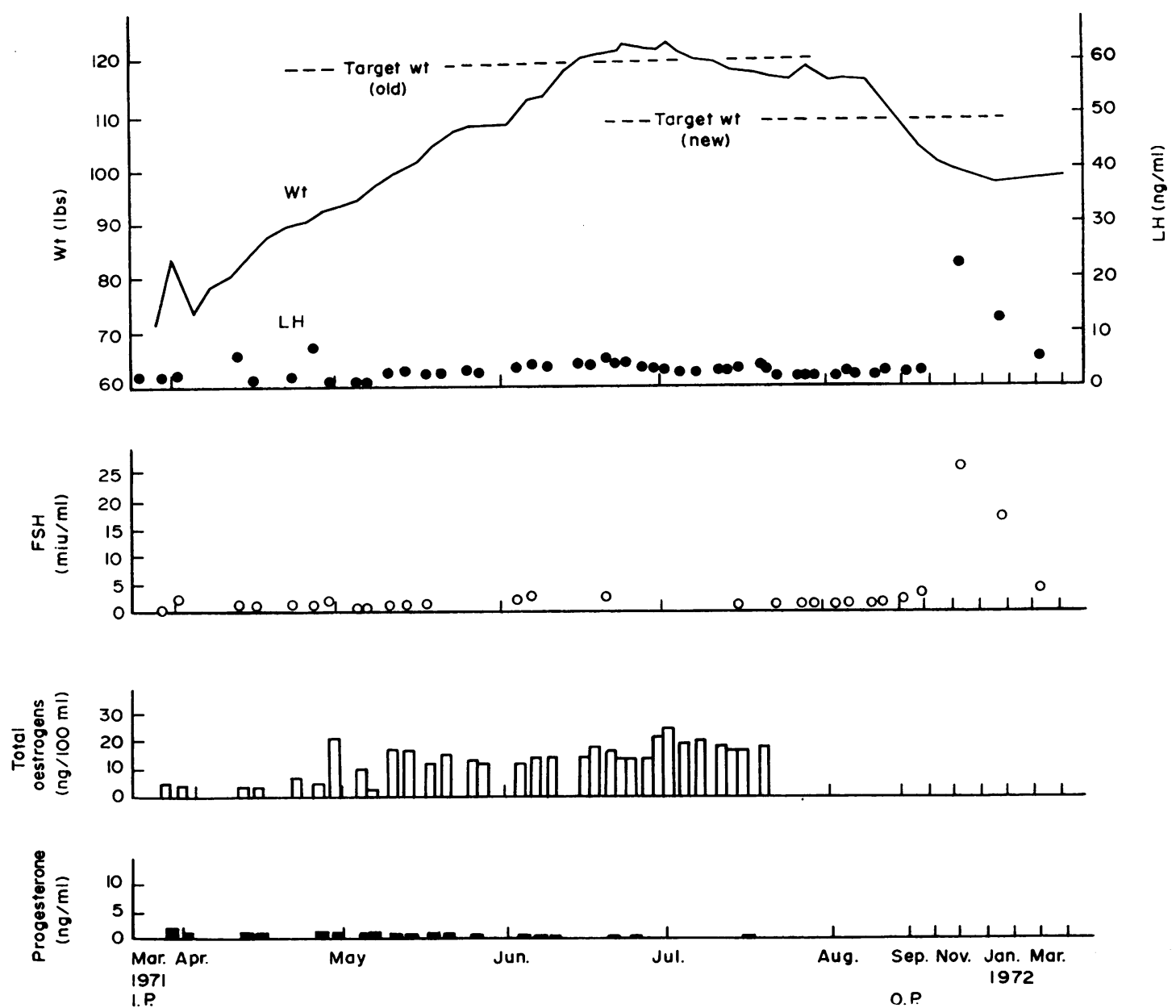

FIG. 1. Case no. 154. 17 years, height $5 \mathrm{ft} 1 \frac{3}{4}$ in. Case nos. 154, 112 and 163 (Figs. 1-3) show a weight gain during treatment which is unaccompanied by marked changes in hormonal levels. These patients were premorbidly obese. The target weight for Case no. 154 was wrongly calculated in the first instance.

TABLE 1. Some data concerning age, weight and LH activity in relation to restoration of weight to mean premorbid weight (MPMW) levels

\begin{tabular}{|c|c|c|c|c|c|c|}
\hline \multirow[b]{2}{*}{ Case no. } & \multirow{2}{*}{$\begin{array}{c}\text { Age at } \\
\text { investigation }\end{array}$} & \multirow{2}{*}{$\begin{array}{l}\text { Age at } \\
\text { onset of } \\
\text { anorexia } \\
\text { nervosa }\end{array}$} & \multirow{2}{*}{$\begin{array}{l}\text { Feeding } \\
\text { pattern: } \\
\text { abstinence/ } \\
\text { vomiting }\end{array}$} & \multicolumn{2}{|c|}{$\begin{array}{l}\text { *Weight (kg) and } \\
\% \text { of normal }\end{array}$} & \multirow{2}{*}{$\begin{array}{l}\text { Occurrence of one or more LH } \\
\text { peaks or high levels of serum } \\
\text { LH in association with restoration } \\
\text { of weight to MPMW }\end{array}$} \\
\hline & & & & $\begin{array}{r}\text { Before } \\
\text { illness }\end{array}$ & $\begin{array}{l}\text { At time } \\
\text { of LMP }\end{array}$ & \\
\hline 161 & 17 & 16 & Abst. & $\begin{array}{c}68 \cdot 0 \\
(111 \%)\end{array}$ & $\begin{array}{c}57 \cdot 2 \\
(103 \%)\end{array}$ & + \\
\hline 155 & 15 & 14 & Abst. & $\begin{array}{c}52 \cdot 1 \\
(95 \%)\end{array}$ & $\begin{array}{c}50 \cdot 8 \\
(93 \%)\end{array}$ & + \\
\hline 103 & 20 & 16 & Abst. & $\begin{array}{c}50 \cdot 8 \\
(96 \%)\end{array}$ & $\begin{array}{r}49.9 \\
(94 \%)\end{array}$ & + \\
\hline 112 & 16 & 13 & Abst. & $\begin{array}{c}64 \cdot 0 \\
(122 \%)\end{array}$ & $\begin{array}{c}52 \cdot 0 \\
(100 \%)\end{array}$ & - \\
\hline 163 & 15 & 14 & Abst. & $\begin{array}{c}70 \cdot 0 \\
(144 \%)\end{array}$ & $\begin{array}{c}68.0 \\
(140 \%)\end{array}$ & - \\
\hline 154 & 17 & 15 & Abst. & $\begin{array}{c}66 \cdot 7 \\
(130 \%)\end{array}$ & $\begin{array}{c}57 \cdot 2 \\
(114 \%)\end{array}$ & - \\
\hline
\end{tabular}

* Mean matched population weights obtained from Standard Tables (Kemsley, 1966). 
obtained usually at 3- or 4-day intervals throughout the period of the in-patient treatment, and thereafter whenever possible. Plasma was separated within $1 \mathrm{hr}$ of blood collection and stored at $-23^{\circ} \mathrm{C}$.

Plasma $L H$ was estimated by radioimmunoassay using a double antibody technique. The antiserum showed no cross reaction with pure FSH or with thyroid stimulating hormone. The second international reference preparation of human menopausal gonadotrophin (2nd IRP-HMG) was used as a standard. Plasma 'pools' were included with each assay in order to check both intra- and interassay variation.

Plasma FSH was similarly measured by a double antibody radioimmunoassay. The antibody used showed a small degree $(4 \%)$ of cross reaction with pure LH which, for the purposes of this study, was considered negligible. 2nd IRP-HMG was used as a standard. Plasma 'pools' used in the LH assays were also used in all the FSH assays.

Plasma total immunoreactive oestrogens were estimated by the radioimmunoassay techniques of 3 Hotchkiss, Atkinson \& Knobil (1971) without@ chromatographic separation of the oestrogens. The $\subseteq$. antiserum used was relatively specific for oestradiol with only a $5 \%$ cross reaction with oestrone.

Plasma progesterone was estimated by competitive protein binding (Johansson, 1969).

\section{Results}

In three patients (Case nos. 154, 112 and 163) with anorexia nervosa no obvious increases in LH levels $\vec{\circ}$ and no typical preovulatory peaks were recorded at any time during the period of weight gain or itsw maintenance over several months (Figs. 1-3). In? one of these subjects (Case no. 154) however, there was some evidence of a temporary increase in plasmaLH as her weight fell $10 \%$ below the target weight after having been maintained at this level for some months. From Table 1 it can be seen that the premorbid weights of these patients were considerablyo higher than the means of matched populations ando
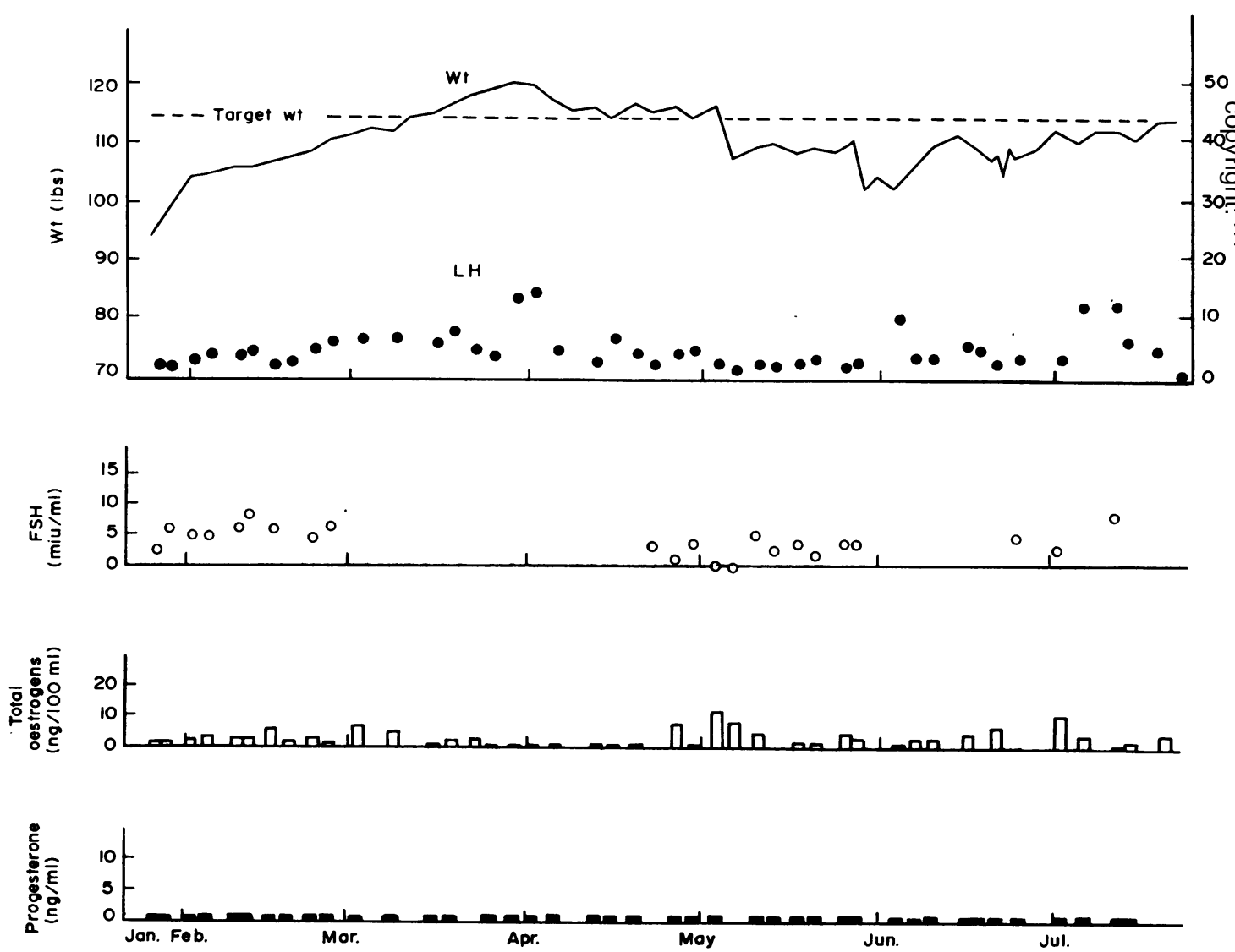
1971 I.P.

Fig. 2. Case no. 112. 16 years, height $5 \mathrm{ft} 4$ in. 

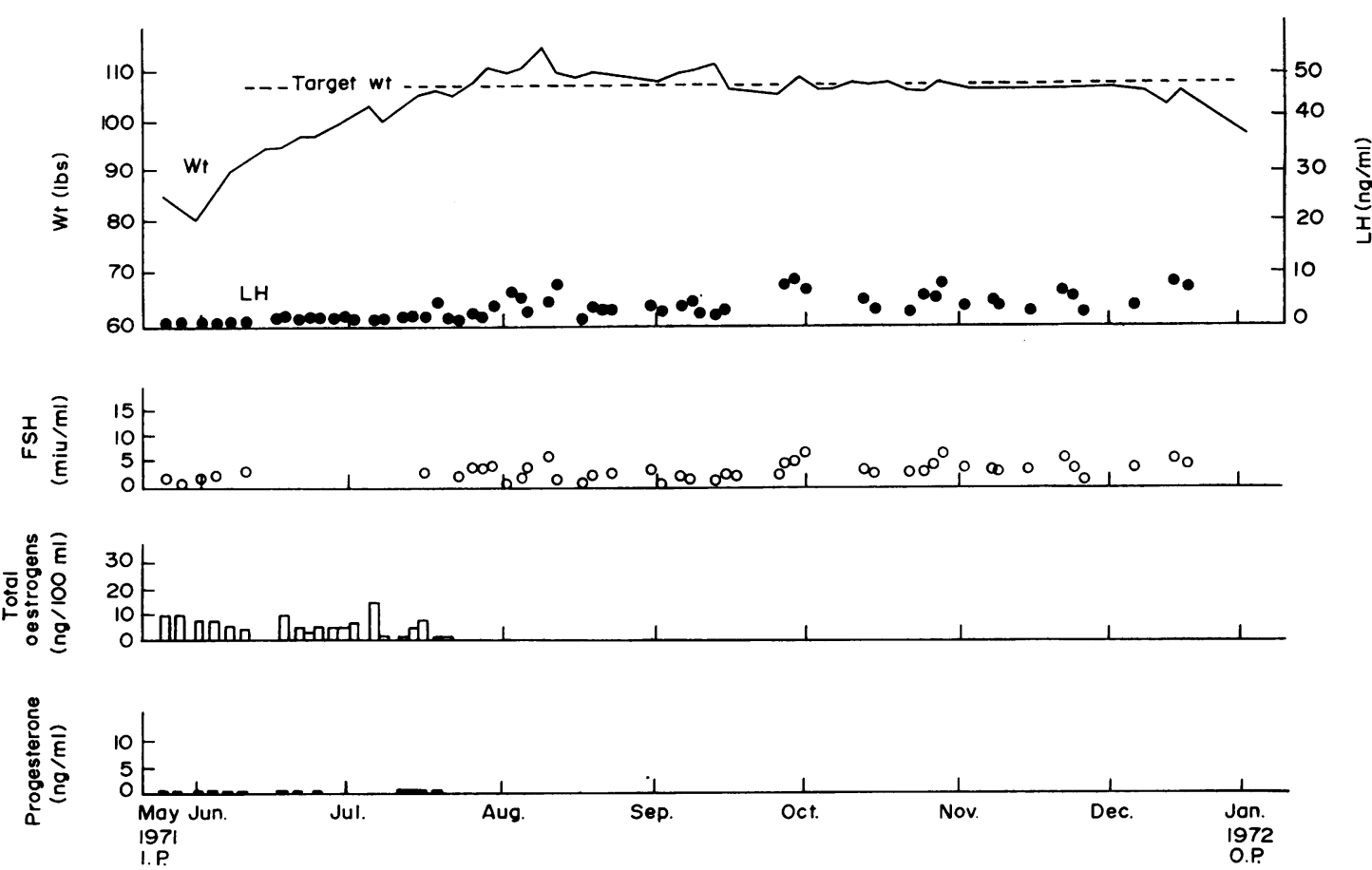

Fig. 3. Case no. 163. 15 years, height $5 \mathrm{ft} 2 \mathrm{in}$.

also that, at the time of their LMP, their weights had been above such levels. In three other patients (Case nos. 161, 155 and 103) there was evidence of considerable LH activity occurring for the first time as weight increased to within $20 \%$ or so of the target weight (Figs. 4-6). At this time occasional LH levels occurred which appeared to reach peak proportions, particularly in patient no. 103, who commenced to menstruate regularly during the course of treatment. The premorbid weights of these patients were close to matched population mean weights (Table 1).

Plasma FSH levels tended to be higher in those subjects who had displayed an increase in LH levels. Raised FSH levels were found in patient no. 154 coincidentally with the single phase of high plasma LH levels, to which reference was previously made.

Total oestrogens tended to remain low in most subjects throughout the investigation although they were within the range of values observed for the early follicular phase of a normal menstrual cycle. In one patient (Case no. 154) oestrogen levels appeared to increase coincidentally with a gain in weight, although a concomitant increase in gonadotrophic levels was not observed. In only one patient (Case no. 103), who began to menstruate after weight gain, was there evidence of cyclical activity; however, Case no. 161 may have had a mid-cycle peak of oestrogen which was not apparently followed by
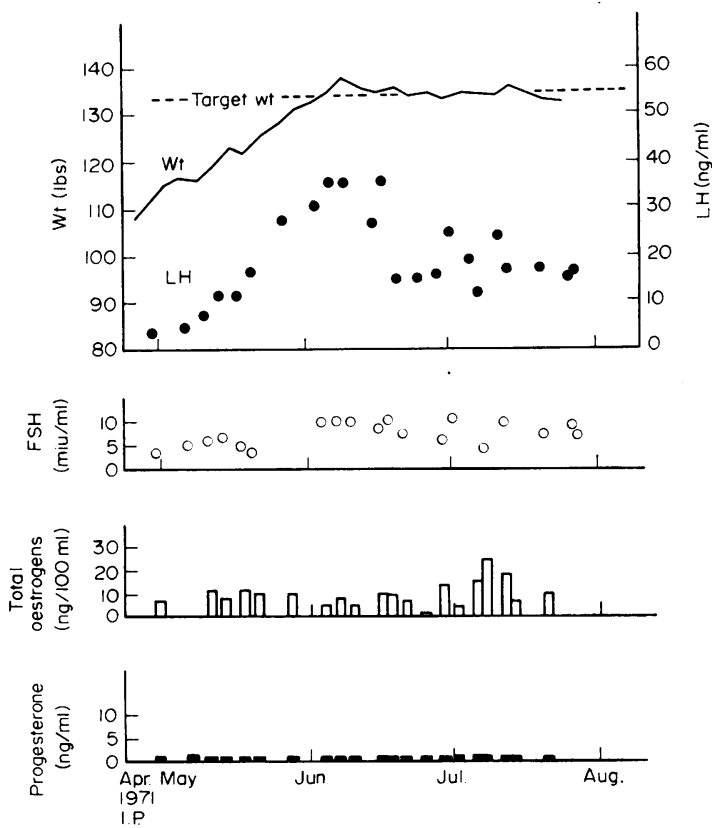

FIg. 4. Case no. 161. 17 years, height $5 \mathrm{ft} 10$ in. Case nos. 161, 155 and 103 (Figs. 4-6) show marked increases of plasma gonadotrophins coincidental with weight gain during treatment. Apparently only Case no. 103 shows evidence of steroid and gonadotrophic cyclicity. These patients had 'normal' premorbid weights. 

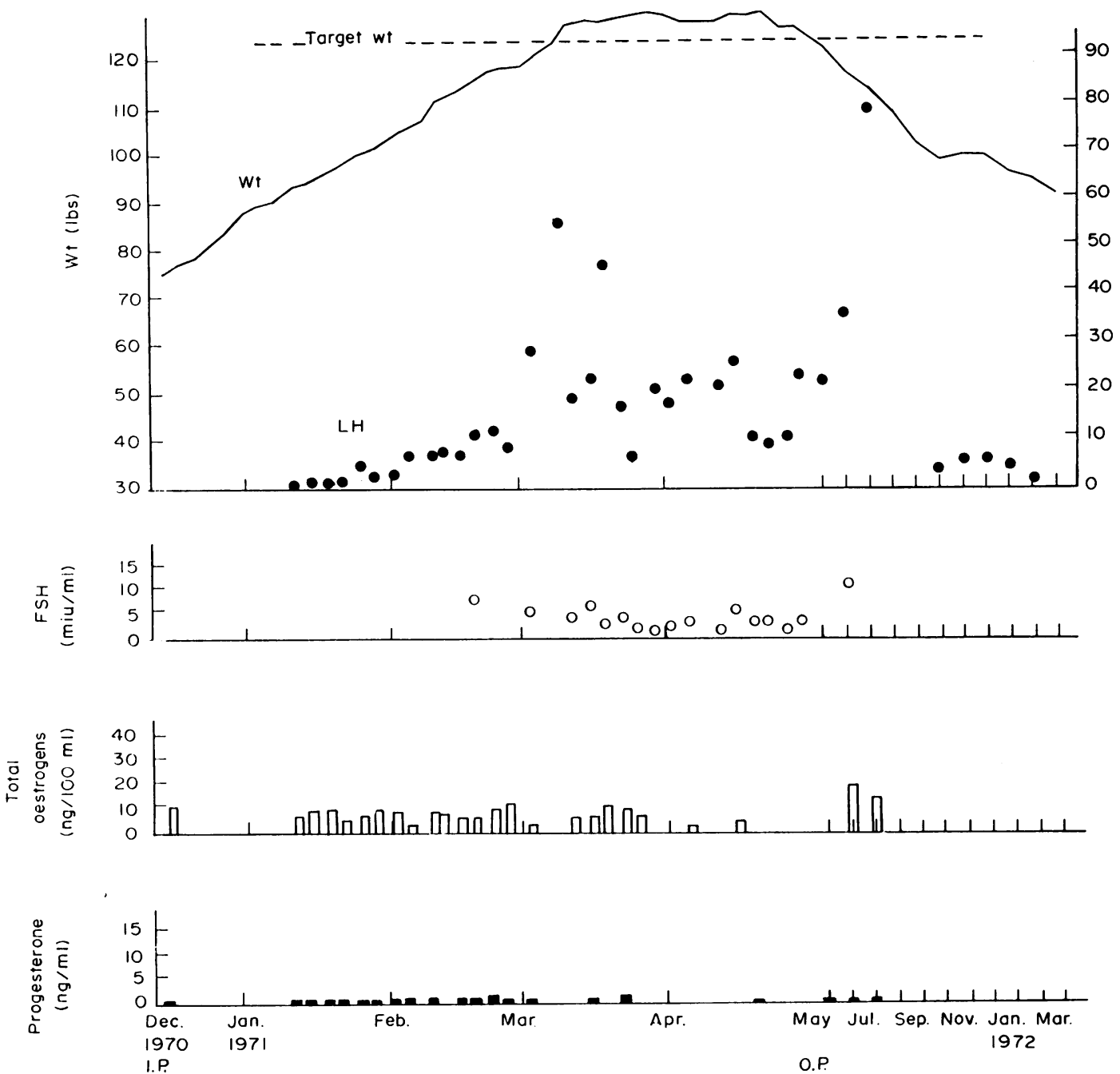

FIg. 5. Case no. 155.15 years, height $5 \mathrm{ft} 6 \frac{1}{2}$ in.

peak levels of gonadotrophins or a progesterone response.

Although sampling was incomplete the data suggests that plasma progesterone levels remained low (i.e. within the range of values for the follicular phase of a menstrual cycle) in almost all the patients throughout the investigation.

\section{Discussion}

Of the six patients with anorexia nervosa who were studied, three had increased levels of LH and FSH with occasional peak values towards the end of the period of weight gain, while one returned to cyclical activity. These patients were characterized by having had normal premorbid weights. Three other patients who did not show a rise in plasma LH levels or, apparently, any gonadotrophic peaks on restoration of their weights to normal levels were markedly obese premorbidly and had experienced their last menstrual periods at weights well above theit matched population mean weight. In spite of the fact that a full daily assessment of hormone levels was not possible these findings suggest that, at least initially, the nutritional stimulus to renewed gonado스 trophic activity in the individual patient appears to $\sigma^{\omega}$ depend upon her premorbid weight. However? although cyclical activity appears not to be alway immediately re-established in the premorbidly obese patients merely by restoration of their weight to matched population mean levels, it has been re ported that over a longer period of time (e.g. a yeart such activity often returns if the patients manage to 


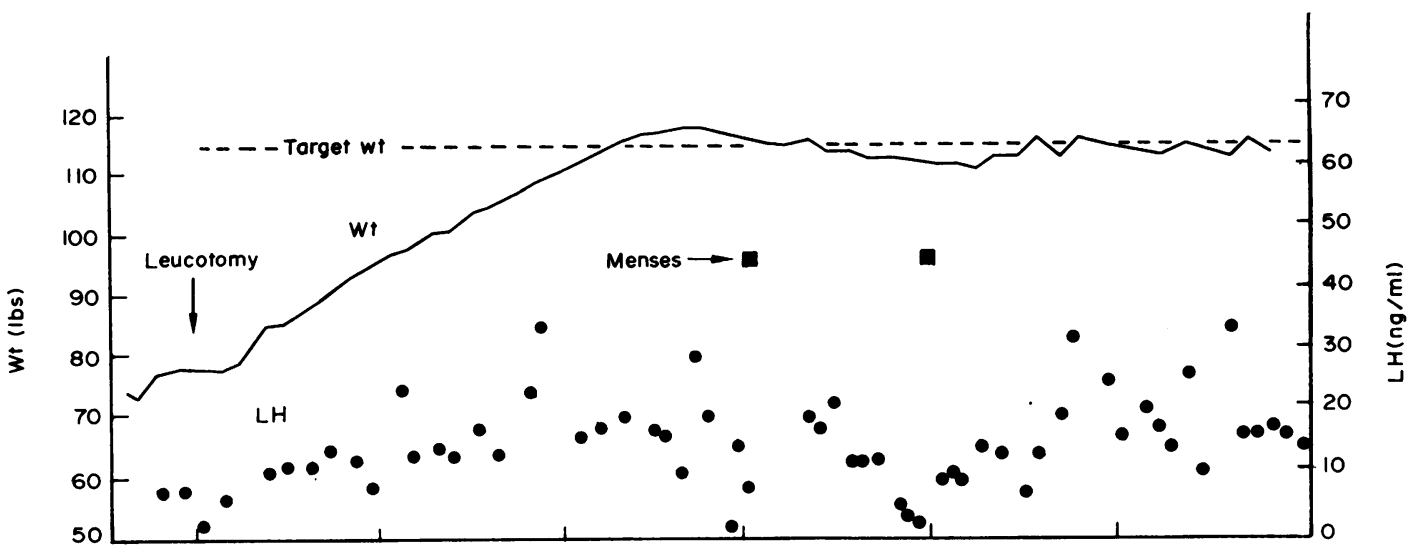

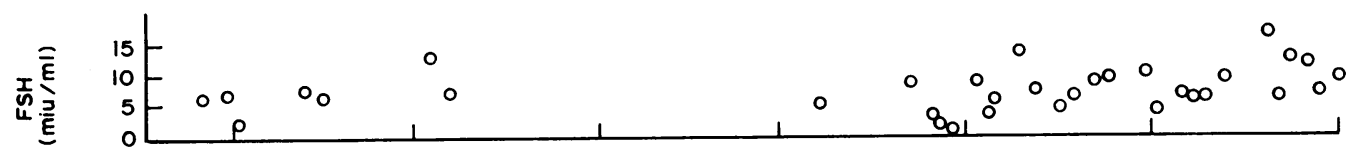

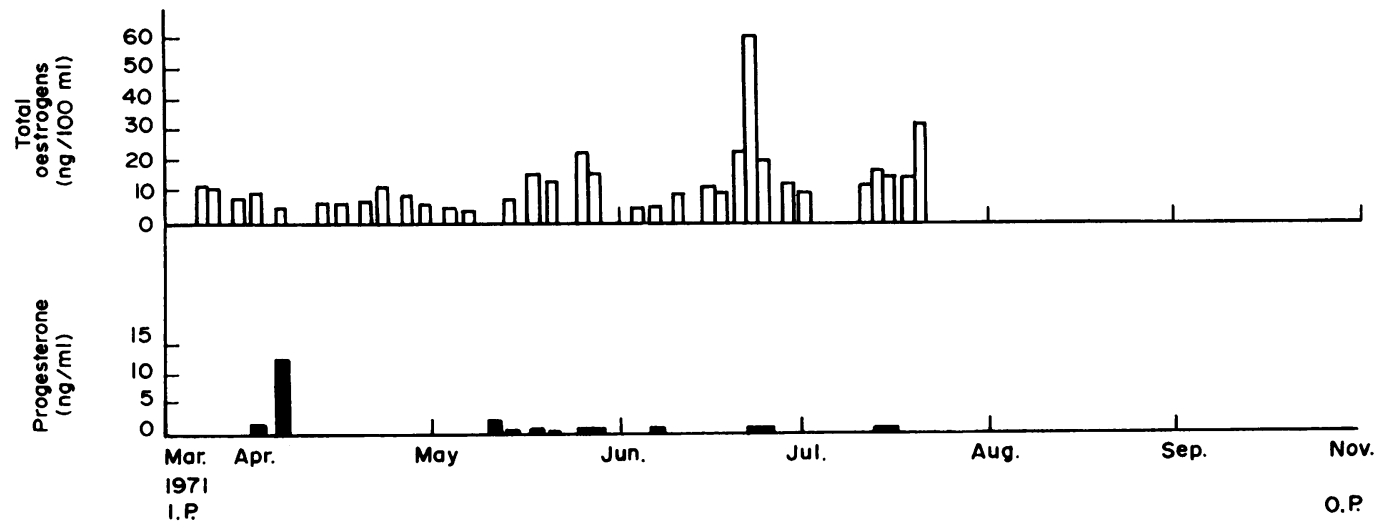

Fig. 6. Case no. 103. 20 years, height $5 \mathrm{ft} 4$ in.

maintain a normal post-illness weight along with a normal dietary intake and adequate social adjustment (Crisp \& Stonehill, 1971).

It has been shown that the LH response to clomiphene citrate in patients with anorexia nervosa is dependent on their weight. Patients with low weights are unresponsive to the drug, whilst those whose weight has been completely or partially restored show the expected response (Marshall \& Russell Fraser, 1971; Beumont, 1972). On the evidence of these findings it has been suggested that hypothalamic activity in the early stages of anorexia nervosa is abnormal and recovers during weight gain. However, clomiphene is used to test the function of the hypothalamic-pituitary axis (Newton \& Dixon, 1971) and does not test specifically the function of the anterior pituitary in terms of gonado- trophic output. Nevertheless, we are in agreement that the more primary defect in anorexia nervosa is likely to be at the hypothalamic level and that it is governed by both psychological and nutritional factors, especially carbohydrate starvation.

In anorexic patients during weight gain it has been reported that urinary oestrogens (Bell et al., 1966) and plasma oestradiol (Beumont, 1972) increase coincidentally with the increase in LH levels. In two out of our three patients in whom LH levels increased along with a gain in weight, a concomitant increase in ovarian steroids during the period of investigation did not apparently occur. This finding suggests the possibility that in certain patients ovarian tissue may be unresponsive, at least initially, to the rising levels of gonadotrophin. Two years later, however, these two patients are doing well and have regular men- 
strual cycles. Meanwhile, if this initial unresponsivity is caused by a lowered nutritional status then pituitary tissue might be expected to be similarly affected. A study of anorexic patients is now in progress to determine whether anterior pituitary activity when stimulated specifically by the gonadotrophic releasing hormone is in fact altered during the initial course of treatment involving restoration of weight to matched population mean levels as described above.

\section{Acknowledgments}

We thank the nursing staff of the psychiatric unit at Atkinson Morley's Hospital for their expert help with the treatment programme and the patients for their co-operation.

We also thank Dr W. Butt for a gift of purified FSH and FSH antiserum, Dr C. A. Paulsen for HCG antiserum, Dr D. Exley for oestradiol antiserum, and the National Institute for Medical Research, Mill Hill, London, for RIA standards. The expert technical assistance of Mrs J. Mattock and Mr E. J. Fox is gratefully acknowledged. The work was supported in part by a grant P3689 (to P.C.B.M.) from the Wellcome Trust.

\section{References}

Bell, E.T., Harkness, R.A., Loraine, J.A. \& Russell, G.F.M. (1966) Hormone assay studies in patients with anorexia nervosa. Acta endocrinologia, 51, 140.

Beumont, P. (1972) Personal communication.
CRISP, A.H. (1967) Anorexia nervosa. Hospital Medicine May, 713.

CRISP, A.H. (1970) Anorexia nervosa 'feeding disorder'c 'nervous malnutrition' or 'weight phobia'? World Review. of Nutrition and Dietetics, 12, 452 .

CRISP, A.H. (1973) The Nature of Anorexia Nervosa. Royal College of Physicians, Edinburgh, Publication No. 42.

CRISP, A.H. \& STONEHILl, E. (1971) Relation between aspects․ㅗ. of nutritional disturbance and menstrual activity ife primary anorexia nervosa. British Medical Journal, 3 149.

Hotchkiss, J., Atkinson, L.E. \& Knobil, E. (1971) Tims course of serum oestrogen and luteinising hormone (LH) concentrations during the menstrual cycle of the rhesus monkey. Endocrinology, 89, 177.

Johansson, E.D.B. (1969) Progesterone levels in periphera plasma during the luteal phase of the normal humang menstrual cycle measured by rapid competitive protein binding technique. Acta endocrinologia, 61, 592.

KEMSLEY, W.F.F. (1951-52) Body weight at different ages and heights. Annals of Eugenics, 16, 316.

Marshall, J.C. \& Russell Fraser, T. (1971) Amenorrhea in anorexia nervosa: assessment and treatment witlf clomiphene citrate. British Medical Journal, 4, 590.

Newton, J. \& Dixon, P. (1971) Site of action of clomiphend and its use as a test of pituitary function. Journal of Obstetrics and Gynaecology of the British Empire, 78, 812.

RAKOFF, A.E. (1968) In: Endocrinology and Human Behavious (Ed. by R. P. Michael). Oxford University Press, London

Russell, G.F.M. (1970) In: Modern Trends in Psychologica Medicine (Ed. by J. H. Price), vol. 2. Butterworths? London. 